\title{
Incidence of unnatural deaths in Transkei sub-region of South Africa (1996-2015)
}

\author{
BL Meela* \\ ${ }^{a}$ Department of Laboratory Medicine and Pathology, Walter Sisulu University, Mthatha, South Africa \\ *Email:meelbanwari@yahoo.com
}

Background: Unnatural deaths are a serious and preventable public health problem in South Africa. Such an event is more than the death of an individual who has died in an unnatural way. It has a negative and long-lasting impact on family members as well as on society as a whole.

Objective: To study the pattern of unnatural deaths in the Transkei sub-region of South Africa.

Method: A record review was undertaken from 1996 to 2015 of 24693 medico-legal autopsies performed at Mthatha Forensic Pathology Laboratory.

Results: At the Mthatha Forensic Pathology Laboratory, 24693 autopsies were performed between 1996 and 2015 on people who had died unnatural deaths. The average rate of unnatural death is 205 per 100000 per year in this region. The figure is 160 per 100000 among males and 44 per 100000 among females. The rate of unnatural death has increased from 153 per 100000 in 1996 to 260 per 100000 in 2015. In two-thirds (69\%) of cases, the cause of death is related to trauma. Slightly less than half (45\%) of the victims in this study were murdered.

Conclusion: There is an increasing trend of unnatural deaths in the Mthatha region of South Africa. The male-to-female ratio is 3.8:1, and about half (48\%) of the victims were between 11 and 30 years old. This situation needs the urgent attention of the law enforcement agencies.

Keywords: unnatural deaths, traumatic deaths, violent deaths

\section{Introduction}

Every year, over a million and a half people worldwide die from preventable acts of violence: 800000 suicides, 50000 homicides and 300000 war deaths. ${ }^{1}$ Injury accounted for $9 \%$ of the world's deaths in 2000 . More than $90 \%$ of such deaths occur in low- and middle-income countries worldwide. Road traffic injuries are responsible for the highest mortality rates from injury. ${ }^{2}$

South Africa ranks number one in Africa in respect of unnatural deaths, with 59935 deaths due to injury in 2000, which is an overall death rate of 157.8 per 100000 of the population. ${ }^{3}$ This rate is higher than the African continental average of 139.5 per 100000 of the population and nearly twice the global average of 86.9 per 100000 of the population. ${ }^{4}$ Nearly half of the deaths due to injury in South Africa are caused by interpersonal violence, ${ }^{3}$ four and a half times the proportion worldwide. ${ }^{5}$

South Africa faces a heavy burden of unnatural deaths arising from violence and injury. In 2000, violence and unintentional injuries combined were the second leading cause of death. ${ }^{3}$ One of the largest threats to the South African community is the high levels of crime. During 2010/11 approximately 2.1 million serious crime cases were registered in the Republic of South Africa. ${ }^{6}$ Every day, around 50 murders, 100 rapes and 500-plus violent assaults are officially recorded in a population of 50 million. $^{7}$

Data from death certificates and the National Injury Mortality Surveillance System (NIMSS) further show that more than a quarter of such deaths are due to road traffic injuries, with the remainder attributable to self-inflicted injuries, fires, drowning and falls. ${ }^{3}$ Every year an estimated 3.5 million people seek health care for non-fatal injuries, ${ }^{5}$ half of which are caused by violence. ${ }^{8}$ The study carried out by the author showed that the incidence of violent unnatural death in this region is a cause for concern. The total number of unnatural deaths reported between 1996 and 2004 was $7303 . .^{9}$ The purpose of this study is to highlight the incidence of unnatural deaths, related to gender and different age groups, in the Transkei region of South Africa.

\section{Method}

Mthatha Forensic Pathology Laboratory is the only laboratory in this region catering for more than half a million of the population in the region of Mthatha. It is attached to the Nelson Mandela Academic Hospital, which is the only teaching hospital in this province. This again is attached to the Walter Sisulu University Medical School, and all medico-legal cases in this region of South Africa are examined there. A total number of 24693 autopsies were conducted between 1996 and 2015. The details of names, addresses, age, gender, date of autopsy and cause of death were recorded in the post-mortem register. The locations were not accurately recorded in the post-mortem register, but most of the deceased came from rural areas, and from a low socio-economic background. Fourteen forensic officers are engaged in collecting corpses round the clock from 17 police stations in four municipalities. These are the OR Tambo, Mhlontlo, Chris Hani and Mbashe municipal areas, comprising about 200 square kilometres.

The OR Tambo municipality is the largest, and is covered fully by 10 police stations. Mhlontlo municipality has four police stations, Chris Hani municipality two and Mbashe municipality one. The combined population was 439091 in 1996, but it has been increasing by an average of $3 \%$ annually. We excluded conceptus material and foetuses, as their age and gender were not indicated in the postmortem registers. In total 440 cases were found where no age was indicated, and these were therefore excluded from the study of age groups. It is difficult to determine the cause of death in cases of advanced putrefied human remains and therefore these were excluded from study. These people were generally found dead, and 
Table 1: Estimated unnatural deaths in the Mthatha area of South Africa by gender (1996-2015)

\begin{tabular}{|c|c|c|c|c|c|c|c|}
\hline \multirow[t]{2}{*}{ Year } & \multirow{2}{*}{$\begin{array}{l}\text { Estimated } \\
\text { population }\end{array}$} & \multicolumn{2}{|c|}{ Females $(n=5332)$} & \multicolumn{2}{|c|}{ Males $(n=19361)$} & \multicolumn{2}{|c|}{ Total $(n=24693)$} \\
\hline & & $\begin{array}{c}\text { No. of un-natural } \\
\text { deaths }\end{array}$ & $\begin{array}{l}\text { Unnatural } \\
\text { deaths per } \\
100000\end{array}$ & $\begin{array}{c}\text { No. of un- } \\
\text { natural deaths }\end{array}$ & $\begin{array}{c}\text { Un-natural } \\
\text { deaths per } \\
100000\end{array}$ & $\begin{array}{l}\text { No. of un-natural } \\
\text { deaths }\end{array}$ & $\begin{array}{c}\text { Unnatural } \\
\text { deaths per } \\
100000\end{array}$ \\
\hline 1996 & 439091 & 122 & 28 & 548 & 125 & 670 & 153 \\
\hline 1997 & 452264 & 211 & 47 & 567 & 125 & 778 & 172 \\
\hline 1998 & 465832 & 220 & 47 & 569 & 122 & 789 & 170 \\
\hline 1999 & 479807 & 167 & 35 & 553 & 115 & 720 & 150 \\
\hline 2000 & 494201 & 193 & 38 & 841 & 170 & 1034 & 208 \\
\hline 2001 & 509027 & 156 & 31 & 812 & 160 & 968 & 190 \\
\hline 2002 & 524298 & 172 & 33 & 810 & 155 & 982 & 187 \\
\hline 2003 & 540027 & 204 & 38 & 901 & 167 & 1105 & 205 \\
\hline 2004 & 556227 & 180 & 32 & 836 & 150 & 1016 & 183 \\
\hline 2005 & 572914 & 289 & 51 & 962 & 168 & 1251 & 219 \\
\hline 2006 & 590102 & 352 & 60 & 929 & 157 & 1281 & 217 \\
\hline 2007 & 607805 & 338 & 56 & 917 & 151 & 1255 & 207 \\
\hline 2008 & 626039 & 332 & 53 & 863 & 138 & 1195 & 191 \\
\hline 2009 & 644820 & 286 & 44 & 947 & 147 & 1233 & 191 \\
\hline 2010 & 664165 & 378 & 57 & 1094 & 165 & 1472 & 222 \\
\hline 2011 & 684089 & 338 & 49 & 1027 & 150 & 1365 & 200 \\
\hline 2012 & 704612 & 345 & 49 & 1295 & 184 & 1640 & 233 \\
\hline 2013 & 725751 & 385 & 53 & 1649 & 227 & 2034 & 281 \\
\hline 2014 & 747523 & 335 & 45 & 1574 & 211 & 1909 & 256 \\
\hline 2015 & 769949 & 329 & 43 & 1667 & 217 & 1996 & 260 \\
\hline Average & 589927 & 267 & 44 & 968 & 160 & 1235 & 205 \\
\hline
\end{tabular}

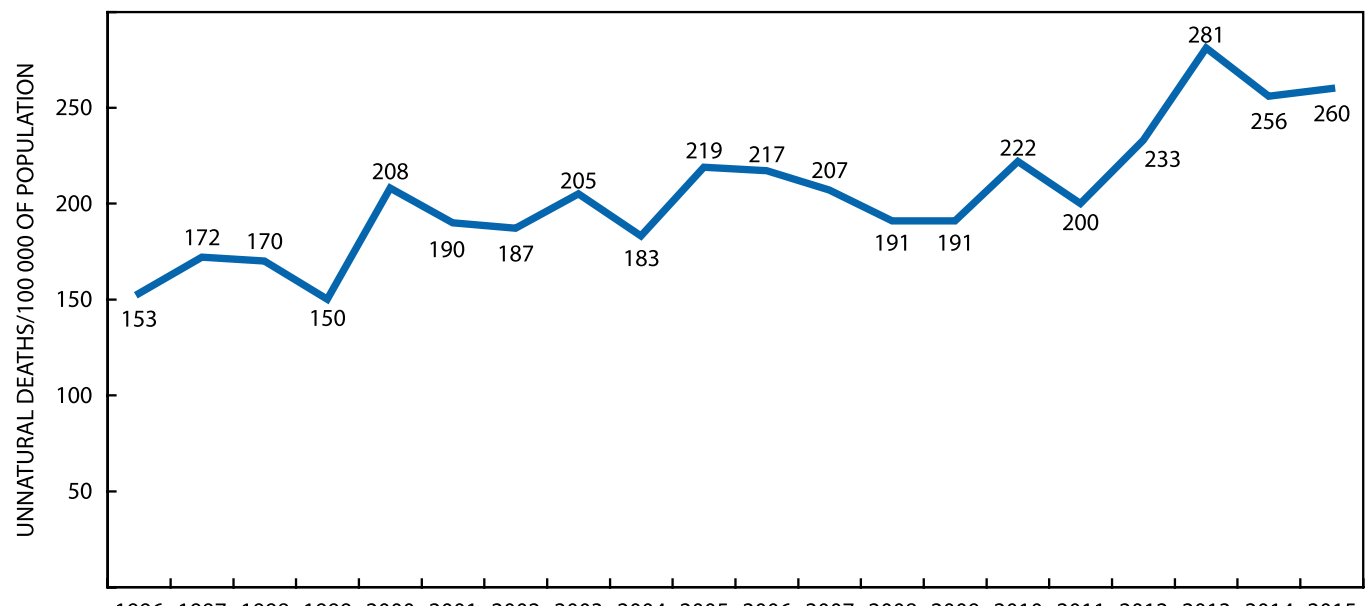

Figure 1: Unnatural death rate per 100000 of population in the Transkei region of South Africa $(n=24693)$.

the forensic officers indicated the cause of death as collapse in the post-mortem register. Traumatic deaths considered in this study are motor vehicle accidents (MVA), stab injuries, firearm wounds and assault (blunt force trauma). Other causes of death, however, are arbitrarily considered non-traumatic, such as hanging, drowning, poisoning, burns, falls from a height, being struck by lightning and gas suffocation. The terms 'gunshot' and 'firearm' are used interchangeably and mean the same. Data were collected on a sheet of paper designed to record the post-mortem number, year, gender and cause of death. These data were transferred to the Excel ${ }^{\circledR}$ computer program (Microsoft Corp, Redmond, WA, USA) and analysed using SPSS $^{\circledast}$ software (SPSS Inc, Chicago, IL, USA).

\section{Results}

Between 1996 and 2015, 24693 autopsies were performed on victims of unnatural deaths brought to Mthatha Forensic Pathology Laboratory. The average rate of unnatural deaths is 205 per 100000 per year in this region (Table 1 and Figure 1). The rate of unnatural death increased from 153 per 100000 in 1996 to 260 per 100000 in 2015 (Table 1 and Figure 1). Classified by gender, the rate increased from $125 / 100000$ (1996) to $217 / 100$ 000 (2015) among males and 28/100 000 (1996) to 43/100 000 (2015) among females (Table 1 and Figure 2). The highest (281/100 000 per year) number occurred in 2013 and the lowest (153/100 000 per year) in 1996 (Table 1 and Figure 1). The average 
Table 2: Ranking by percentage of cause of death by gender in Umtata area, South Africa 1996-2015

\begin{tabular}{|c|c|c|c|c|c|c|}
\hline \multirow[t]{2}{*}{ Rank } & \multicolumn{2}{|c|}{ Males $(n=19361)$} & \multicolumn{2}{|c|}{ Females $(n=5332)$} & \multicolumn{2}{|c|}{ Total $(n=24693)$} \\
\hline & $\begin{array}{l}\text { Cause of } \\
\text { death }\end{array}$ & (n) \% & $\begin{array}{l}\text { Cause of } \\
\text { death }\end{array}$ & $(n) \%$ & $\begin{array}{l}\text { Cause } \\
\text { of } \\
\text { death }\end{array}$ & $(n) \%$ \\
\hline 1 & Stabbing & $\begin{array}{c}(4376) \\
22.5\end{array}$ & MVA & $\begin{array}{c}(1631) \\
30.45\end{array}$ & MVA & $\begin{array}{l}(5896) \\
23.77\end{array}$ \\
\hline 2 & MVA & $\begin{array}{c}(4265) \\
21.93\end{array}$ & Gunshot & $\begin{array}{l}(650) \\
12.13\end{array}$ & Stabbing & $\begin{array}{c}(4830) \\
19.47\end{array}$ \\
\hline 3 & Gunshot & $\begin{array}{c}(2921) \\
15.02\end{array}$ & Poisoning & $\begin{array}{c}(530) \\
9.89\end{array}$ & Gunshot & $\begin{array}{c}(3571) \\
14.40\end{array}$ \\
\hline 4 & Assault & $\begin{array}{c}(2255) \\
11.60\end{array}$ & Stabbing & $\begin{array}{c}(454) \\
8.47\end{array}$ & Assault & $\begin{array}{c}(2667) \\
10.75\end{array}$ \\
\hline 5 & Hanging & $\begin{array}{c}(-1376) \\
7.08\end{array}$ & Assault & $\begin{array}{c}(412) \\
7.69\end{array}$ & Hanging & $\begin{array}{c}(1555) \\
6.27\end{array}$ \\
\hline 6 & Drowning & $(-934) 4.8$ & Drowning & $\begin{array}{c}(325) \\
6.07\end{array}$ & $\begin{array}{l}\text { Drown- } \\
\text { ing }\end{array}$ & $\begin{array}{c}(1259) \\
5.08\end{array}$ \\
\hline 7 & Collapse & $\begin{array}{c}(1519) \\
7.81\end{array}$ & Collapse & $\begin{array}{l}(529) \\
9.87\end{array}$ & Collapse & $\begin{array}{c}(2048) \\
8.26\end{array}$ \\
\hline 8 & Poisoning & 3.13 & Burns & $\begin{array}{c}(266) \\
4.97\end{array}$ & $\begin{array}{l}\text { Poison- } \\
\text { ing }\end{array}$ & $\begin{array}{c}(1130) \\
4.59\end{array}$ \\
\hline 9 & Burns & (423) 2.18 & Lightning & $\begin{array}{c}(192) \\
3.58\end{array}$ & Burns & $\begin{array}{l}(689) \\
2.78\end{array}$ \\
\hline 10 & $\begin{array}{l}\text { Fall from } \\
\text { height }\end{array}$ & (357) 1.84 & Hanging & $\begin{array}{c}(179) \\
3.34\end{array}$ & $\begin{array}{l}\text { Fall from } \\
\text { height }\end{array}$ & $\begin{array}{c}(492) \\
1.98\end{array}$ \\
\hline 11 & Lightning & (273) 1.40 & $\begin{array}{l}\text { Fall from } \\
\text { height }\end{array}$ & $\begin{array}{c}(135) \\
2.52\end{array}$ & $\begin{array}{l}\text { Light- } \\
\text { ning }\end{array}$ & $\begin{array}{c}(465) \\
1.87\end{array}$ \\
\hline \multirow[t]{2}{*}{12} & $\begin{array}{l}\text { Gas suffo- } \\
\text { cation }\end{array}$ & $\begin{array}{l}(53) \\
0.27\end{array}$ & $\begin{array}{l}\text { Gas suffo- } \\
\text { cation }\end{array}$ & $\begin{array}{l}(29) \\
0.54\end{array}$ & $\begin{array}{l}\text { Gas suf- } \\
\text { focation }\end{array}$ & $\begin{array}{l}(82) \\
0.33\end{array}$ \\
\hline & $\begin{array}{l}\text { All causes } \\
\text { of deaths }\end{array}$ & 100 & $\begin{array}{l}\text { All causes } \\
\text { of death }\end{array}$ & 100 & $\begin{array}{l}\text { All } \\
\text { causes of } \\
\text { death }\end{array}$ & 100 \\
\hline
\end{tabular}

females, the commonest is MVA $(1631,30.5 \%)$, followed by gunshot wounds $(650,12.1 \%)$, poisoning $(530,9.9 \%)$, stab injury (454, 8.5\%) and assault (412, 7.7\%) (Table 2 and Figure 4).

Most of those who died an unnatural death in the Transkei subregion of South Africa (25.1\%) were males in the 21 to 30-year age group, followed by those aged 11-20 (15.1\%), and 31-40 (14.2\%) (Figure 5). The ratio between males and females was 3.8:1 in these deaths.

\section{Discussion}

The Republic of Transkei was a former black homeland, which was merged with South Africa when the apartheid era ended in 1994. People became free politically, but in general poverty has not declined since 1994. ${ }^{10}$ Poverty is severe in the former Bantustans, such as the Transkei region. Some $73 \%$ of the rural people in the Eastern Cape were living on less than R300 per month in 2005/06, and more than half of them on less than R220 per month. ${ }^{10}$ Poverty has complex mechanisms and relationships with unnatural deaths.

Little has been published on unnatural deaths in South Africa. The NIMSS study is the only source of information, but the study is restricted to metropolitan areas such as Cape Town, Johannesburg, Durban and Port Elizabeth. Transkei sub-region is rural or semi-rural and the availability of health care and transport services is limited. Women and young children are the most vulnerable members of this impoverished society. The number of unnatural deaths recorded in the period 1996-2015 was 24 693 (see Tables 1 and 2). This is almost equal to the number of people killed in crashes of 50 jumbo jets, each carrying 500 passengers, in a period of 20 years and equates to nearly three crashes a year. A single plane crash like that will cause a big hue and cry worldwide, but the world is not even aware of the deaths

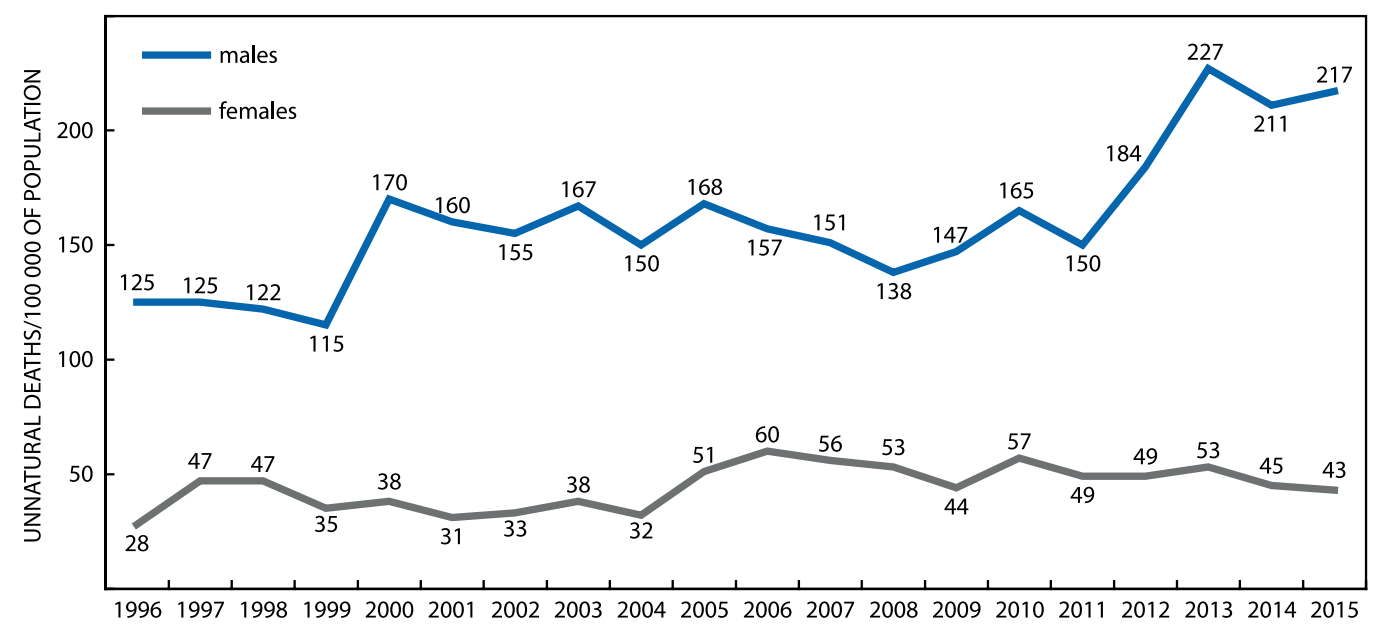

Figure 2: Male vs. female unnatural deaths per 100000 of population in the Transkei region of South Africa ( $n=24693$ ).

rate of unnatural death was 160 per 100000 among males, and 44 per 100000 among females (Table 1 and Figure 2).

Of 24693 autopsies, 19361 (79\%) were performed on males and 53361 (21\%) on females (Table 2). MVA was the commonest cause of death $(5896,23.9 \%)$, followed by stab injuries (4 830, 19.5\%), gunshot wounds (3 571, 14.5\%), assault (2 667, 10.8\%), and hanging (1 555, 6.3\%) (Table 2 and Figure 3). Stab injury (4 376, $22.5 \%)$ is the leading cause of death among males, followed by MVA (4 265, 21.9\%), gunshot wounds 2 921, 15.0\%), assault (2 255, $11.6 \%$ ) and hanging (1376, 7.1\%) (Table 2 and Figure 4). Among of such a large number of people in this region.

The average rate of unnatural deaths is 205 per 100000 per annum in this study (see Table 1 and Figure 1). This is at least 7.1 times higher than the global average, which is 28.8 per 100000 of the population. ${ }^{11}$ South Africa, which has witnessed a dramatic reduction in political violence following its first democratic election in 1994, has reported a rate of fatal violence more than five times the global average. ${ }^{4}$ The rate of these violent deaths has not reduced in the Transkei sub-region of South Africa. More people 


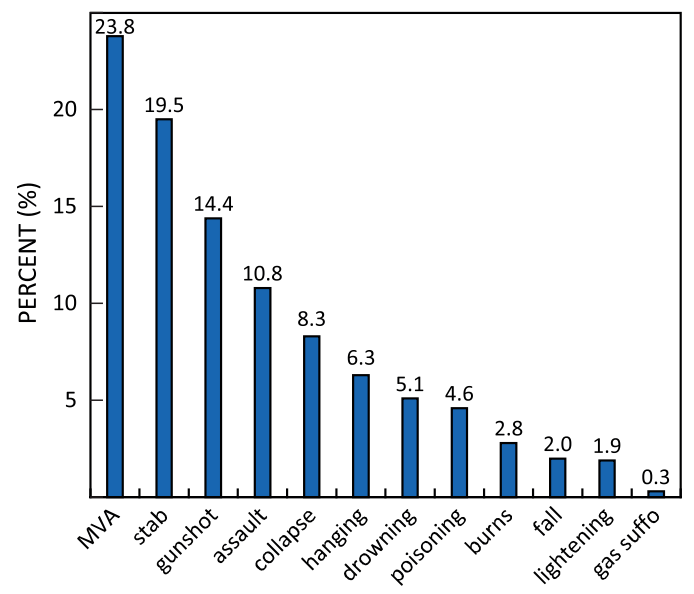

Figure 3: Percentages of causes of death in the Transkei region of South Africa from 1996 to 2015 ( $n=24$ 693). was a periodical (every five years) increase in unnatural deaths from 1996 to 2015 except in 2013 (see Figure 1). This pattern correlates with unnatural deaths among males (see Figure 2). To understand the dynamics of unnatural deaths in the Transkei sub-region, one has to understand the increasing level of poverty and unemployment. In $2006 / 07$, only $16 \%$ of the rural population between the ages of 15 and 64 were employed..$^{10}$ Most of the people were working in mines, but the mining industry is undoubtedly in a worse state now than in 2006/07, because of the 2008/09 global recession. In 2009, the South African economy shed over a million jobs, resulting in a decline in the employment rate from $45 \%$ to $41 \% .{ }^{10}$ The recession in the country affected mainly the poor and marginalised (rather than the rich). Employment in rural regions such as the Transkei dropped below $15 \%$. That is, for every 100 people between the ages of 15 and 64 in the former Bantustans, not even 15 earned an income from a wage. ${ }^{10}$

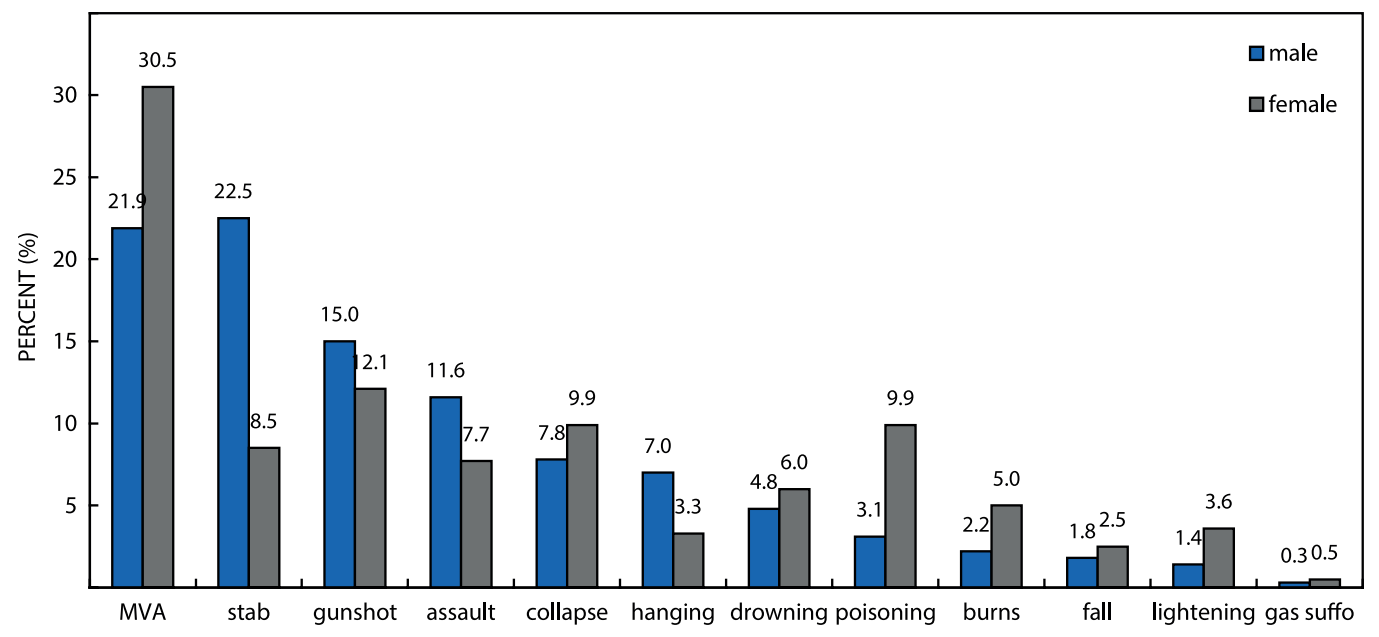

Figure 4: Percentages of males vs. females cause of death in the Transkei region of South Africa from 1996 to 2015 ( $n=24$ 693).

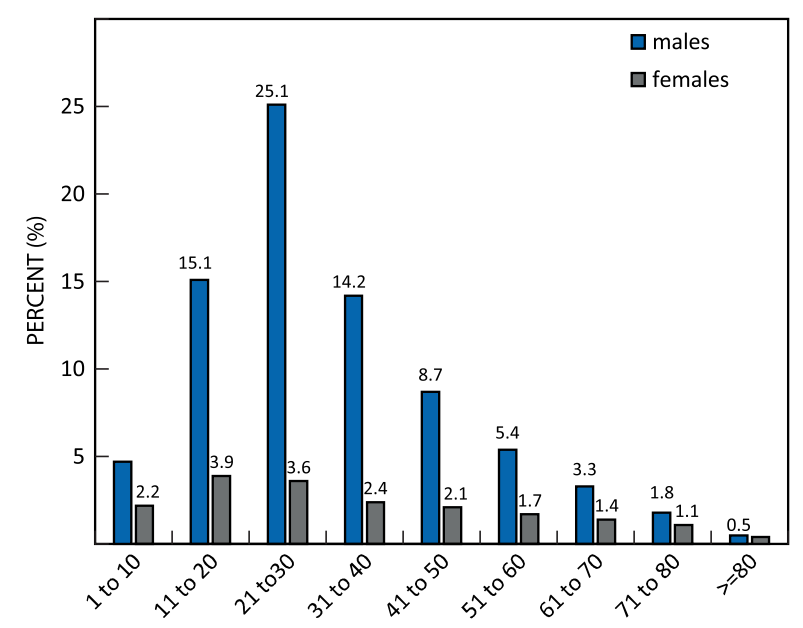

Figure 5: Percentages of non-natural deaths among different age groups in the Transkei region of South Africa $(n=24253)$.

are dying unnatural deaths in this sub-region of South Africa than in some of the war-torn countries such as Afghanistan and Libya.

There was an increase in unnatural deaths from 153 per 100000 per annum in 1996 to 260 per 100000 in 2015 (see Table 1). There
Estimates of the total number of unnatural deaths in South Africa range between 70000 and 80000 annually, which accounts for between $12 \%$ and $15 \%$ of all mortality. ${ }^{12}$ This figure includes 1 235 (1.80\%) unnatural deaths among the Transkei sub-region's population of about 0.58 million (1.1\%) every year. This equates to 1 in 398 deaths in the Transkei sub-region to 1 in 625 in the rest of South Africa. The chance of unnatural death is more than one and a half times ( $x$ 1.6) as high in this region as in the rest of South Africa (see Table 2).

Annual police statistics reveal that violent crime has steadily increased since 2012, with the 2014/15 police statistics showing that the murder rate has increased by $4.6 \%$ from 2013 to $1414 .{ }^{13}$ The most common four causes of death that are traumatic in nature account for more than two-thirds (68.5\%) of all unnatural deaths (see Figures 3 and 4). Of this number, more than half (44.7\%) were murdered (see Figures 3 and 4). South Africa is known for its excessive violence and deaths due to unnatural causes. It is a disturbing fact that these deaths are most painful, yet preventable. It is generally presumed that unnatural deaths are prevalent in urban areas of South Africa, but this is not necessarily so. The rural population is poorer than the urban one, and therefore takes more risks in the procurement of food. Poverty is probably the main underlying cause of this high number of unnatural deaths in this region, as it perpetuates death through multiple mechanisms. 
Alcohol consumption is very high, especially over weekends and at night. In South Africa, 76\% of all deaths after interpersonal violence have been shown to be alcohol-related. ${ }^{14}$ An earlier (2006) study carried out by the author showed that the incidence of alcohol-related traumatic deaths is high in the Transkei subregion. ${ }^{15}$ HIV/AIDS is increasing at an ever more alarming rate, and the focus placed on this tends to divert attention from other health problems. Thus, thorough attention needs to be paid to the reduction of violent and/or traumatic deaths in the country. ${ }^{16}$

The number of non-traumatic deaths (16\%) was also more than two and a half times ( 5544 males/2 067 females) higher in males in this study (see Table 2 ). The highest percentage (23.26\%) of deaths was reported among 21 to-30-year-olds (Figure 5). Levels of youth violence vary widely between countries and within countries from one region to another. Mortality rates from homicide among 10 to 29-year-olds range from 84.4 per 1000000 of the population in Columbia to less than 1 per 100000 in Japan. ${ }^{17}$ In the Transkei subregion, about $48 \%$ of unnatural deaths were recorded in the 11 to 30-year age group, which represents about 99 deaths per 100000 of the population. Most (45\%) of these were homicides. This means that the murder rate in this region among 11 to 30 -year-olds is an average of 45 per 100000 per year.

There is a culture of crime in this part of South Africa. Families are segregated and have no family value system. Children have either a single parent or no parents. Many live with an aunt or uncle. People are poor and the illiteracy rate is very high. In this region apartheid was practised rigorously. The region has produced a leader at national and international level, but people's living conditions are worse than before. The scars of apartheid are reflected in their lives. One will find hardly any family in which no one has died an unnatural death. Black men are usually the perpetrators as well as the victims. Most of the time they die while procuring food, either by stealing or robbing someone's house. People are risking their lives on a daily basis for survival. Childhood is very harsh and traumatised, and this is reflected in people's later life. People are not scared of going to prison, as they have more food security there and do not risk dying of hunger.

\section{Limitations}

The population has been estimated with the help of Statistics South Africa, but it is difficult to estimate the actual population because of the geographical position of serving police stations. The annual growth in the population is believed to be $3 \%$, which may not be accurate. The lack of location, socio-economic backgrounds of deceased, ethnicity, and educational status is also a limitation in this study. Deaths as the result of domestic violence were not found in the post mortem register, and this has added to the limitations.

\section{Conclusion}

There was an incremental increase in unnatural deaths in the Transkei sub-region of South Africa from 1996 to 2015. Traumatic deaths are the biggest contributor to this, especially homicides. More than half of those killed were young males between 11 and 40 years of age. Unnatural death is a serious public health issue in this sub-region, especially due to MVA and murders. Poverty, illiteracy and unemployment are the factors fuelling these unnatural deaths in a vicious manner. The high prevalence of HIV/AIDS in this region has partly diverted attention from the issue of unnatural deaths. The government and law enforcement agencies must take up the challenge of reducing the high number of unnatural deaths in the Transkei sub-region of South
Africa. There is a need for further analysis to account for the rural vs. urban comparison, socioeconomic factors, educational level, and poverty to make a study meaningful.

\section{Ethical issue}

The author has ethical permission for collecting data and publication (approved project No. 4114/1999) from the Ethical Committee of the University of Transkei.

Acknowledgement - The author would like to thank to all staff of the Forensic Pathology Laboratory for helping to collect data, and providing information on police stations in this region. The author would also like to thank the South African Statistics Department at Mthatha for providing a population estimate of all the police stations.

\section{References}

1. World Health Organization (WHO). Milestones in changing the face of violence prevention, Geneva: WHO; 2005.

2. World Health Organization (WHO). The injury chart book. A graphical overview of the global burden of injuries, Geneva: WHO; 2002.

3. Norman R, Matzopoulos R, Groenewald P, et al. The high burden of injuries in South Africa. Bull World Health Org. 2007;85:695-702. https://doi.org/10.2471/BLT.00.000000

4. Matzopoulos R, Norman R, Bradshaw D. The burden of injury in South Africa: fatal injury trends and international comparisons. In: Suffla S, Van Niekerk A, Duncan N, editors. Crime violence and injury prevention in South Africa: development and challenges. Tygerberg: MRC-UNISA Crime, Violence and Injury Lead Programme; 2004. p. 9-12.

5. Peden M, McGee K, Sharma G. The injury chart book: a graphical overview of the global burden of injuries. Geneva: World Health Organization; 2002.

6. South African Police Services. Crime Report 2010/2011 [cited 2016, Jun 3]. Available from: http://www.info.gov.za/view/ DownloadFileAction?id=150105.

7. Crime in South Africa, it won't go away. The Economist (2009, October 1). Available from: http://www.economist.com/node/1456421.

8. Matzopoulos R, Prinsloo M, Butchart A, et al. Estimating the South African trauma caseload. Int J Inj Contr Saf Promo. 2006;13:49-51. https://doi.org/10.1080/15660970500036382

9. Meel BL. Unnatural deaths among children in Transkei region of South Africa. Med Sci Law. 2007;48(3):232-6.

10. Westaway A. Rural poverty in Eastern Cape Province: legacy of apartheid or consequence of contemporary segregationism? Dev South Afr. 2012;29(1):115-25. https://doi.org/10.1080/037683 5X.2012.645646

11. World Health Organization (WHO). World report on violence and health. Geneva: World Health Organization; 2001.

12. Matzopoulos R, Seedat M, Cassim M. A profile of fatal injuries in South Africa. Fourth Annual Report of the National Injury Mortality Surveillance System, 2002 [cited 2016, Oct 31] (MRC-UNISA). Available from: http://www.mrc.ac.za/crime/nimssannual2002.pdf.

13. Gun free South Africa. Making South Africa a safer country by reducing gun violence [cited 2016, Oct 30]. Available from: http:// www.gfsa.org.za/latest-news/media-releases/.

14. Van Der Spuy JW. Trauma, alcohol and other substances. S Afr Med J. 2000;90:244-6.

15. Meel BL. Alcohol-related traumatic deaths in Transkei region, South Africa. Internet Journal of Medical Update (IJMU). 2006;1 (1): 14-9.

16. Meel BL. Incidence and pattern of violent and/or traumatic deaths between 1993 and 1999 in the Transkei region of South Africa. J Trauma Injury Infect Crit Care. 2004;57(1):125-9. https://doi. org/10.1097/01.TA.0000101492.77304.0E

17. WHO. World report on violence and health; 2002 [cited 2016, Nov 6]. Available from: whqlibdoc.who.int/publications/2002/9241545615_ eng.pd. 